\title{
Investigation of the association between family members' satisfaction with patient care in the Intensive Care Unit, spirituality and resilience
}

lokasti Papathanasiou

401 Geniko Stratiotiko Nosokomeio Athenon

Vasileios Tzenetidis

2510 Geniko Nosokomeio Aeroporias

Athanasios Nikolentzos

Hellenic Open University

Pavlos Sarafis ( $\square$ pavlos.sarafis@cut.ac.cy)

Cyprus University of Technology

Maria Constantinou

Cyprus University of Technology

Maria Malliarou

University of Thessaly

Research

Keywords: Intensive Care Unit, relatives, satisfaction, perceived stress, resilience, spirituality

Posted Date: August 6th, 2020

DOI: https://doi.org/10.21203/rs.3.rs-52226/v1

License: (9) (i) This work is licensed under a Creative Commons Attribution 4.0 International License.

Read Full License 


\section{Abstract}

Background: The admission of a patient in the Intensive Care Unit (ICU) is a traumatic experience for the patient himself and his support group which mainly consists of his family members. The psychological burden of the family members increases, as they experience negative feelings. The implementation of family-centered care helps family members to satisfy their needs, eliminates psychological impact and improves patient's health outcomes. The aim of this study is to investigate the family members' satisfaction with patient care in the ICU, their perceived stress, spirituality and resilience.

Methods: One hundred and four family members of patients admitted in the ICU for greater than 48 hours between January and March 2019 were enrolled. The questionnaire included the following psychometric tools: the Family Satisfaction with care in the Intensive Care Unit scale, the Perceived Stress Scale, the Connor - Davidson Resilience Scale, the Daily Spiritual Experience Scale and the Acute Physiology and Chronic Health Evaluation Scale.

Results: The mean value of satisfaction with care was $88,9 \%$, of satisfaction with decision making was $79,1 \%$ and of the overall satisfaction was $85 \%$. Resilience was associated with perceived stress $(p<0,001)$ and with spirituality $(p=0,019)$. Spirituality was associated with satisfaction with care $(p=0.013)$, with satisfaction with decision making $(p=0,018)$ and with the overall satisfaction $(p=0,003)$.

Conclusions: Family members were highly satisfied. Those with higher spirituality score were more satisfied and those who were more resilient had less perceived stress. These data suggest that interventions should aim at increasing resilience and providing spiritual assistance to family members of ICU treated patients.

\section{Background}

Critical illness and its consequences, the hospitalization in the ICU and the intensive nature of the care provided, lead the family into a multidimensional crisis (1). The admission of a patient in the ICU affects all members of its family $(2,3)$. The family members during the hospitalization of their relative and after discharge from the ICU feel vulnerable, experience acute stress, Post Traumatic Stress Disorder (PTSD), anxiety, complicated grief and depression $(4,5)$. Perceived stress is the result of an individual's interaction with the environment. Stress is not triggered by single events but by the way the individual objectively assesses the environment, the events, and by whether he considers them uncontrollable and threatening $(6,7)$.

Family members of ICU treated patients are often required to educate, inform, support, and take care of their relative (8). Often, they must make decisions on the part of them (9). However, they also have their own needs. In some studies, their needs are divided in five categories: support, comfort, patient proximity, information and confirmation (10-13). In others, they are divided into four categories: cognitive, emotional, social and practical (14). Family members' needs satisfaction assessment is done from two different perspectives: satisfaction with the care provided and satisfaction with decision-making (15). 
Epidemiology does not give clear explanations of the factors and mechanisms that protect individuals who, even though they are exposed to compounding factors they are not affected by their adverse effects. Resilience refers to the positive adaptation and to the protective factors that modify the risks and limit their negative impact on outcomes (16). Resilience is described as a person's ability to cope with and overcome stressful and traumatic events, as the ability to adapt in critical situations or to resist risks throughout life and to recover from the challenges (17). It protects from mental disorders, such as depression, anxiety and acute stress $(18,19)$. However, there is a conflict as to whether it is a dynamic state or an innate trait (20). Studies conducted in different contexts claim that resilience is an acquired characteristic $(21,22)$.

Spirituality is a multidimensional concept, which has a broader meaning than religion (23). Lately, it has turned out to be an important aspect for patients hospitalized in ICU and their relatives (24). Spirituality refers to the perceptions and the means that one uses when trying to satisfy his/her inner quests, to improve as a human being and to give meaning in his/her life. It also refers to aspects of personal life and includes the transcendental, the divine, the sacred and the experiences that are not perceived by the basic senses (25). As for the relatives of ICU treated patients, the correlation with some higher power helps them understand and accept the pain while providing comfort and relief $(23,26)$.

The aim of this study is to investigate the family members' satisfaction with patient care in the ICU, their perceived stress, spirituality and resilience. The experience of the family members of ICU treated patients will be understood. Interventions will be identified, the implementation of which will help increase family members' satisfaction with the care provided, reduce the psychological burden and make their experience less painful.

\section{Methods}

\section{Participants and Procedure}

A cross-sectional study was conducted at the 401 General Military Hospital of Athens. Family members of patients admitted in the ICUs between January 2019 and March 2019 for greater than 48 hours were eligible to be enrolled. The hospital included coronary, cardiosurgery and general ICU. The participants were family members who visited the patient in the ICU, showed interest in the patient's care, had come in contact with healthcare professionals having formed a complete opinion, were over 18 years of age and could read and understand the Greek language. Up to two members were included from each patient's family. The study excluded relatives of patients who were hemodynamically stabilized and discharged from the ICU or had died in less than 48 hours, who were pregnant and under the age of 18 years.

The questionnaires were given by the primary investigator during ICU visiting time. They were filled in and returned directly or at the next visit. The primary investigator informed the participants about the purpose of the study. Their participation was optional, and the answers were anonymous. Informed consent was obtained from the patients' family members. The study was approved by the Scientific Committee of 401 General Military Hospital of Athens. (Number 1/2029). 
Family members' demographics included age, sex, level of education, place of residence and religion. Categorizing information included relationship with the patient and previous experience in ICU.

The family members' satisfaction was assessed with the Family Satisfaction in the Intensive Care Unit (FS-ICU 24). FS-ICU determines overall satisfaction (24 questions), satisfaction with the quality of care (14 questions) and satisfaction with the decision-making process (10 questions). The total score ranges from 0 to 100 . The higher the score, the greater the satisfaction of the participant $(15,27)$.

The degree to which the participants interpret situations in their lives as stressful was assessed by the Perceived Stress Scale (PSS-14). PSS-14 includes 14 questions related to the frequency of expression of feelings and thoughts during the last month.

The total score ranges from 0 to 56 . The higher the score, the higher the level of perceived stress $(7,28)$.

The Connor-Davidson Resilience Scales (CD-RISC-25) was used to assess resilience. Five factors were measured, personal ability and sufficiency, control, trust in personal instinct and tolerance of negative events, positive attitude towards change and secure relationships and spiritual influence. Participants score 25 statements depending on the extent to which each statement reflects their emotional status over the past month. The score ranges from 0 to 100 . The higher the score, the higher the level of mental resistance $(29,30)$.

The Daily Spiritual Experience Scale (DSES) is related to the person's perception of engagement and interaction with the divine in everyday life. It was used to determine the spirituality of the participants by measuring the frequency in which they consider that they are connected to the divine according to their religion or the spiritual group they belong to. It includes 16 statements that are rated by the participants. The overall score ranges from 16 to 94 . The higher the score, the higher the level of daily spiritual experience (25).

All questioners demonstrate validity and reliability. They have been translated and validated in Greek.

The Acute Physiological and Chronic Health Evaluation Scale (APACHE II), assesses the severity of the disease. It is used to determine the outcome of ICU treated patients in relation to the use of the therapies, to help medical personnel make clinical decisions, to predict hospital mortality and as a communication code for the patients' health condition. The score is calculated from 12 routine physiological parameters: temperature, mean blood pressure, arterial $\mathrm{Ph}$, heart rate, respiratory rate, serum sodium, serum potassium, serum creatinine, white blood cells, hematocrit, Glasgow Coma Scale, oxygenation values and the previous health condition of the patient. The worst values of each parameter recorded on the first 24 hours of hospitalization in the ICU are used for the score calculation. The maximum value is 71 , but no patient has reached 55 points. The higher the value the greater the severity of the disease. (31).

\section{Data Analysis}

Mean values, standard deviations, median, and interquartile ranges were used to describe quantitative variables. Absolute $(\mathrm{N})$ and relative (\%) frequencies were used to describe the qualitative variables. For 
the comparison of quantitative variables between two groups, the non-parametric Mann-Whitney criterion was used. For the comparison of quantitative variables between the two groups, the non-parametric Kruskal-Wallis criterion was used. To control the Type I error, due to the multiple comparisons, the Bonferroni correction was used, according to which the significance level is $0.05 / \mathrm{K}(\mathrm{K}=$ number of comparisons). The correlation coefficient of Pearson or Spearman ( $r$ ) was used to control the relationship of two quantitative variables. The correlation is considered low when the correlation coefficient ( $r$ ) ranges from 0.1 to 0.3 , moderate when it ranges from 0.31 to 0.5 and high when it is greater than 0.5 . Linear regression analysis was used to find independent factors associated with the different scales from which dependency coefficients (b) and their standard errors (SE) occurred. Linear regression analysis was performed for satisfaction using logarithmic transformations. The significance levels were two-sided, and the statistical significance was set to 0.05 . The statistical program Statistical Package for Social Sciences, SPSS 22.0, was used for the analysis.

\section{Results}

\section{Demographic characteristics}

The sample consisted of 104 family members of patients admitted in the coronary, the cardiosurgery and the general ICU of 401 Military Hospital of Athens with an average age of 50.7 years (SD $=13.4$ years). The characteristics of the participants are presented in Table 1.

\section{Table 1: Participants' demographic characteristics}




\begin{tabular}{|c|c|c|c|}
\hline & & $\mathbf{N}$ & $\%$ \\
\hline \multirow[t]{2}{*}{ Gender } & Men & 34 & 32,7 \\
\hline & Women & 70 & 67,3 \\
\hline \multicolumn{2}{|l|}{ Age, (SD) } & $\begin{array}{l}50,7 \\
(13,4)\end{array}$ & \\
\hline \multirow[t]{5}{*}{ Relationship with patient } & Spouse & 25 & 24,0 \\
\hline & Parent & 8 & 7,7 \\
\hline & Brother/Sister & 8 & 7,7 \\
\hline & Son/Daughter & 48 & 46,2 \\
\hline & Other & 15 & 14,4 \\
\hline \multirow[t]{4}{*}{ If other, what } & Nephew & 5 & 4,8 \\
\hline & Son/Daughter in law & 6 & 5,8 \\
\hline & Grandchild & 3 & 2,9 \\
\hline & Cousin & 1 & 1,0 \\
\hline \multirow[t]{2}{*}{ Previous ICU experience } & No & 60 & 57,7 \\
\hline & Yes & 44 & 42,3 \\
\hline \multirow[t]{2}{*}{ Do you live with the patient at the moment } & No & 49 & 47,1 \\
\hline & Yes & 55 & 52,9 \\
\hline \multirow{5}{*}{$\begin{array}{l}\text { If not, then how often do you see the } \\
\text { patient }\end{array}$} & More than once a week & 22 & 44,9 \\
\hline & Once a week & 8 & 16,3 \\
\hline & Once a month & 15 & 30,6 \\
\hline & Once a year & 3 & 6,1 \\
\hline & Less than once a year & 1 & 2,0 \\
\hline \multirow[t]{2}{*}{ Where do you live } & $\begin{array}{l}\text { In the city that the hospital is } \\
\text { located }\end{array}$ & 81 & 77,9 \\
\hline & In a different city & 23 & 22,1 \\
\hline \multirow[t]{5}{*}{ Education level } & Elementary school & 6 & 5,8 \\
\hline & $\begin{array}{l}\text { Secondary school/Institute of } \\
\text { Vocational Training }\end{array}$ & 5 & 4,8 \\
\hline & High school & 49 & 47,1 \\
\hline & University & 31 & 29,8 \\
\hline & Page 6/23 & & \\
\hline
\end{tabular}




\begin{tabular}{|llll|}
\hline \multirow{2}{*}{ Religion } & Master's/PhD & 13 & 12,5 \\
& Christian orthodox & 99 & 95,2 \\
\cline { 2 - 4 } & Atheist & 4 & 3,8 \\
\hline \multirow{2}{*}{$\begin{array}{l}\text { How often do you go to the church or in } \\
\text { other worship places }\end{array}$} & Other & 1 & 1,0 \\
\cline { 2 - 4 } & Every week & 25 & 24,0 \\
\cline { 2 - 4 } & Once a month & 35 & 33,7 \\
\cline { 2 - 4 } & Olmost never & 36 & 34,6 \\
\hline & & 8 & 7,7 \\
\hline
\end{tabular}

$67.3 \%$ of the participants were women and $46.2 \%$ were patients' sons and daughters. $42.3 \%$ had participated in the past as a family member of an ICU treated patient. More than half of them $(52.9 \%)$ lived at the moment with the patient and $77.9 \%$ lived in Athens. Most of the participants $(47,1 \%)$ were secondary school / Institute of Vocational Training graduates and $29.8 \%$ were university graduates. Almost all participants (95.2\%) were Christian Orthodox. $34.6 \%$ of the participants went to the church only on special days and $33.7 \%$ once a month.

\section{Patients' clinical characteristics}

$60.6 \%$ of the patients were hospitalized in the coronary, $26.0 \%$ in the cardiosurgery and $13.5 \%$ in the general ICU. Patients' APACHE II mean score was 17.6 units (SD = 11.0 units).

\section{Correlations between the PSS-14, the DSES and the CD-RISC-25}

The PSS-14 score ranged from 7 to 41 units with an average value of 23.4 units (SD $=7.7$ units).

The DSES score ranged from 19 to 87 points with an average value of 52.3 units (SD $=16.3$ units).

The CD-RISC-25 score ranged from 31 to 100 units with an average value of 70,0 units (SD=12,9 units).

Pearson's correlation coefficients between the PSS-14, the DSES and the CD-RISC-25 are presented in Table 2.

Table 2: Pearson's correlation coefficients between PSS-14, DSES, CD-RISC-25 


\begin{tabular}{|llll|}
\hline & & DSES & CD-RISC-25 \\
\hline PSS-14 & $\mathrm{r}$ & $-0,15$ & $-0,37$ \\
& $\mathrm{P}$ & 0,124 & $<0,001$ \\
DSES & $\mathrm{r}$ & & 0,23 \\
& $\mathrm{P}$ & & $\mathbf{0 , 0 1 9}$ \\
\hline
\end{tabular}

The CD-RISC-25 is negatively and significantly correlated with the PSS-14 ( $p<0.001)$ (Fig 1), and positively and significantly correlated with the DSES $(p=0.019)($ Fig 2$)$.

\section{Family Satisfaction}

Satisfaction with care score ranged from $28.6 \%$ to $100 \%$, with an average of $88.9 \%$ (SD $=14.5 \%$ ). 33 of the participants (35.9\%) were completely satisfied with care. Satisfaction with decision-making score ranged from $27.5 \%$ to $100 \%$, with the average value being $79.1 \% .10$ of the participants $(9.7 \%)$ were completely satisfied with the decision making. Overall satisfaction score ranged from $38.5 \%$ to $100 \%$, with an average of $85 \%(S D=13.9 \%) .8$ of the participants $(8.8 \%)$ were totally satisfied.

Only the DSES was found to be significantly associated with satisfaction with care $(p=0.007)$, satisfaction with decision making $(p=0.025)$ and with overall satisfaction $(p=0.009)$ (Table 3$)$.

Table 3: Pearson's correlation coefficients between PSS-14, DSES, CD-RISC-25 and satisfaction with care, decision making and overall satisfaction

\begin{tabular}{|lllll|}
\hline & & $\begin{array}{l}\text { Satisfaction with care } \\
(\%)\end{array}$ & $\begin{array}{l}\text { Satisfaction with decision } \\
\text { making (\%) }\end{array}$ & $\begin{array}{l}\text { Overall satisfaction } \\
(\%)\end{array}$ \\
\hline PSS-14 & $\mathrm{R}$ & $-0,07$ & $-0,06$ & $-0,05$ \\
\cline { 2 - 5 } & $\mathrm{P}$ & 0,535 & 0,572 & 0,630 \\
\hline DSES & $\mathrm{R}$ & 0,28 & 0,22 & 0,27 \\
& $\mathrm{P}$ & $\mathbf{0 , 0 0 7}$ & $\mathbf{0 , 0 2 5}$ & $\mathbf{0 , 0 0 9}$ \\
\hline CD-RISC- & $\mathrm{R}$ & 0,19 & 0,18 & 0,16 \\
\hline 25 & $\mathrm{P}$ & 0,073 & 0,071 & 0,119 \\
\hline
\end{tabular}

Specifically, the greater the participants' spirituality, the more satisfied they were. The correlations between the DSES and the satisfaction with care, decision making, and overall satisfaction scores are 
presented in Figures 3, 4 and 5.

The participants who lived in a different city than where the hospital was, rated significantly higher satisfaction with care scores.

Satisfaction with decision-making score was found to vary considerably depending on the ICU that the patient was admitted in. After the Bonferroni correction it was found that participants whose relatives were hospitalized in cardiosurgery ICU had a significantly higher score, determining more satisfaction with decision making, compared to those whose relatives were admitted in the coronary ICU $(p=0.018)$.

Participants who lived in a different city than where the hospital was, were significantly more satisfied overall. After the Bonferroni correction, the total satisfaction score was not significantly different depending on the ICU that the patient was admitted.

There was a significant positive correlation between the satisfaction with care score $(p=0.006)$, decision making score $(p=0.011)$ and overall satisfaction score $(p=0.007)$ and the patients' APACHE II score. Specifically, higher APACHE II score was associated with greater satisfaction with care, decision making and overall satisfaction.

\section{Multivariable linear regressions}

Multivariable linear regressions were performed to estimate the relationship between participants' satisfaction with care, decision making, overall satisfaction and several independent covariates (participants' demographic data, patient data, PSS-14, DSES, and CD-RISC-25).

Only the DSES was found to be significantly associated with the participants' satisfaction with care $(p=$ $0.013)$, with decision making $(p=0.018)$ and with overall satisfaction $(p=0.003)$. Specifically, the greater the spirituality of the participants, the more satisfied they were with care, decision making and in total. Satisfaction was not associated with participants' age, gender, prior ICU experience, relation to patient, city of residence, type of ICU, patients' APACHE II score, PSS-14 or CD-RISC-25 (al p>0.05).

Multivariable linear regressions were performed to estimate the relationship between PSS-14, DSES, CDRISC-25 and participants' demographic data, and patient data.

Only the participants' gender was found to be significantly associated with the PSS-14. Specifically, women had a higher score of 3.44 units, indicating more stress, compared to men. The PSS-14 score according to the participants gender is presented in Figure 6.

The participants' relationship with the patient and the frequency that they went to the church relate independently to the DSES. The participants who cared for their brother or sister had a higher score by 14.10 units, indicating significantly more spirituality, compared to the participants who cared for their spouse. In addition, the more frequent the participants went to the church, the higher their spirituality. The DSES score according to the frequency of going to the church is presented in Figure 7. 
The gender and the participants' relationship with the patient relate independently to the CD-RISC-25. Women's score was lower by 6.20 units, indicating significantly less resilience compared to men's. The participants who cared for their parent had a lower score by 11.41 units, indicating significantly less resilience compared to those who cared for their spouse. The CD-RISC-25 sore according to the participants' gender is presented in Figure 8.

\section{Discussion}

According to the present study, the average satisfaction with care rate is $88.9 \% .35 .9 \%$ of the participants were completely satisfied with the care provided. The average value of satisfaction with decision-making is slightly lower, $79.1 \%$. A small percentage of the participants $(9.7 \%)$ declared absolutely satisfied with decision making. Average overall satisfaction was calculated at $85 \%$, while $8.8 \%$ of the participants were completely satisfied. Recent studies have addressed the issue of family members' satisfaction of ICU treated patients. Kourti et al (2014) carried out a study in a public hospital in Athens and Chalkidi et al (2016) conducted a study in a public hospital in northern Greece both used the FS-ICU 24, Carlson et al (2015) used the FSCCQ and Jacob et al (2016) used the FS-ICU 24 both conducted studies in hospitals in United States. High satisfaction with care scores were reported in all studies (32-35)

The findings of the present study show that satisfaction with care, decision making, and overall satisfaction are not related to the participant's gender, age or relationship with the patient. Similarly, Chalkidi et al (2016) found that participant's age and relationship with the patient is not associated with satisfaction with care and decision-making. In contrast, Sottile et al (2016) demonstrated that spouses expressed more satisfaction than other relatives, while no correlation was found between satisfaction and age, gender and previous ICU experience $(35,36)$.

A significant negative correlation was found between CD-RISC-25 and PSS-14 $(p<0.001)$. This may be due to the fact that resilient participants are able to adapt to stressful situations, use protective mechanisms, modify the risks and limit the negative effects. This corroborates previous findings. According to Sottile et al (2016), individuals with high resilience score experience less stress symptoms (36). According to Min et al (2013) and Davidson et al (2005), resilience protects against mental disorders such as depression, anxiety and acute stress $(18,19)$. The present study provided evidence that CD-RISC-25 is positively associated with DSES ( $p=0.019)$. In agreement, Rahmati et al (2017) demonstrated that the application of spiritual interventions increases resilience (37). Even though the Greek literature concerning spirituality of family members of ICU treated patients is limited, Plakas et al (2011), found that spirituality is the basic source of power and courage for relatives of ICU treated patients and it helps them relieve of negative emotions (38). Literature has also reported that spirituality, and faith in a higher power are used by individuals of any religion in order to manage stressful situations related to health problems (39).

In the present study no significant association was found between the DSES and the PSS-14. However, according to Casarini et al (2009), spirituality was classified as the second most common way to manage stressful situations by relatives of ICU treated patients (26). In addition, according to Schleder et al 
(2013), spirituality prevents and reduces negative emotions (23). Finally, according to Chan \& Twinn, (2007), the shift to religion is one of the basic strategies used by relatives of ICU treated patients when they experience stressful situations (40).

The findings of the present study suggest that the DSES is positively and significantly associated with overall satisfaction, satisfaction with care, and decision-making. This may be due to the fact that participants' connection with a higher power helps them understand and accept pain and discomfort, thus limiting their needs and increasing their satisfaction $(23,26)$. Moreover, it has emerged that CD-RISC25 and PSS-14 are not significantly related to overall satisfaction, satisfaction with care and decisionmaking. Different results have been demonstrated by Sottile et al (2016). They found that resilience is significantly associated with satisfaction from care and decision-making (36). Bailey et al (2010) did not find either a significant correlation between perceived stress and satisfaction with care and decisionmaking (41).

Only gender was found to be significantly associated with PSS-14 $(p=0.050)$. Women had higher scores, indicating more perceived stress than men. Similar results have been demonstrated by PlaszewskaZywko \& Gazda (2012), Paparigopoulos et al (2006), Chui \& Chan (2007) and Pochard et al (2005) (4245). Conversely, according to Anderson et al (2009), stress is associated with young age, low educational level, and is not correlated with gender, ethnicity, religion, or relationship with the patient (9).

The participants' relationship with the patients $(p=0.030)$ and the frequency that they went to the church $(p<0.001)$ were independently associated with the DSES. Participants who were brothers of the patients had higher spirituality score than those who were spouses. Moreover, the more frequently the participants went to the church, the higher their spirituality score. This finding agrees with Plakas et al (2011). They analyzed that spirituality is expressed by visiting places of worship (38).

The participants' gender $(p=0.033)$ and their relationship with the patient $(p=0.046)$ were independently associated with the CD-RISC-25. Women were significantly less resilient than men, and patients' sons and daughters were significantly less resilient than spouses. This may be due to the fact that sons and daughters could not adapt to the critical situation (17). In contrast, Sottile et al (2016) found that resilience is not significantly related to gender (36).

\section{Conclusion}

The main findings of the present study are the significant association between spirituality and satisfaction with care, decision-making and overall satisfaction, the significant association between resilience and spirituality and perceived stress. The findings suggest that by increasing resilience, the perceived stress and the prevalence of PICS-F will be reduced. The results of the study will contribute to the design of interventions aimed at enhancing resilience, limiting perceived stress and promoting spirituality. Family members of ICU treated patients will maintain hope and regain emotional control.

\section{Study limitations}

Page $11 / 23$ 
This study has some limitations. Family members who were not located because they avoided entering in the ICU and those who did not wish to participate might have an importantly lower resilience score that would affect the results. Some relatives were very old and could not answer the questionnaire due to visual and cognitive difficulties. Questionnaire responses may be affected by participants' emotional burden. Finally, this is a cross-sectional study so there is no temporal association between variables.

\section{Declarations}

\section{Ethics approval and consent to participate}

With the 1/2029 record of the meeting, the Scientific Committee of 401 General Military Hospital of Athens approved the study. The participants were informed about the aim of the research. It was explained orally and in writing that their participation was voluntary, the answers were anonymous, they would be used precisely for the purpose of the survey and that the questionnaires would only be accessible to the researcher. Informed consent was obtained from the patients' family members before filling out the questionnaires.

\section{Consent for publication}

Not applicable

\section{Availability of data and materials}

The datasets generated and analyzed during the current study are not publicly available to preserve the privacy of the participants but are available from the corresponding author on reasonable request

\section{Competing interests}

The authors declare that there are no competing interests

\section{Funding}

Not applicable

\section{Authors' contributions}

PS, MC and IP conceived the original idea. IP collected the data and together with MM wrote the paper. VT particularly performed the computations and statistically analyzed the questionnaires' results. Finally AN substantially revised it. All authors have read and approved the manuscript.

\section{Acknowledgements}

We would like to thank the participants for their cooperation. 


\section{Abbreviations}

APACHE Acute Physiology and Chronic Health Evaluation

CD-RISC Connor - Davidson Resilience Scales CD-RISC

DSES Daily Spiritual Experience Scale

FS-ICU Family Satisfaction with care in the Intensive Care Unit

ICU Intensive Care Unit

PICS-F Postintensive Care Syndrome- Family

PSS-14 Perceived Stress Scale

\section{References}

1. Andresen M, Guic E, Orellana A, Diaz MJ, Castro R. Posttraumatic stress disorder symptoms in close relatives of intensive care unit patients: Prevalence data resemble that of earthquake survivors in Chile. J Crit Care. 2015;30(5):1152 e7-11.

2. Buhse M. Assessment of caregiver burden in families of persons with multiple sclerosis. J Neurosci Nurs. 2008;40(1):25-31.

3. McKeown LP, Porter-Armstrong AP, Baxter GD. The needs and experiences of caregivers of individuals with multiple sclerosis: a systematic review. Clin Rehabil. 2003;17(3):234-48.

4. Turner-Cobb JM, Smith PC, Ramchandani P, Begen FM, Padkin A. The acute psychobiological impact of the intensive care experience on relatives. Psychol Health Med. 2016;21(1):20-6.

5. Davidson JE, Jones C, Bienvenu OJ. Family response to critical illness: postintensive care syndromefamily. Crit Care Med. 2012;40(2):618-24.

6. DeLongis A, Folkman S, Lazarus RS. The impact of daily stress on health and mood: psychological and social resources as mediators. J Pers Soc Psychol. 1988;54(3):486-95.

7. Cohen S, Kamarck T, Mermelstein R. A global measure of perceived stress. J Health Soc Behav. 1983;24(4):385-96.

8. Plakas S, Cant B, Taket A. The experiences of families of critically ill patients in Greece: a social constructionist grounded theory study. Intensive Crit Care Nurs. 2009;25(1):10-20.

9. Anderson WG, Arnold RM, Angus DC, Bryce CL. Passive decision-making preference is associated with anxiety and depression in relatives of patients in the intensive care unit. $\mathrm{J}$ Crit Care. 2009;24(2):249-54.

10. Chatzaki M, Klimathianaki M, Anastasaki M, Chatzakis G, Apostolakou E, Georgopoulos D. Defining the needs of ICU patient families in a suburban/rural Greek population: a prospective cohort study. $\mathrm{J}$ Clin Nurs. 2012;21(13-14):1831-9. 
11. Khalaila R. Patients' family satisfaction with needs met at the medical intensive care unit. J Adv Nurs. 2013;69(5):1172-82.

12. Obringer $\mathrm{K}$, Hilgenberg $\mathrm{C}$, Booker $\mathrm{K}$. Needs of adult family members of intensive care unit patients. $J$ Clin Nurs. 2012;21(11-12):1651-8.

13. Hinkle JL, Fitzpatrick E. Needs of American relatives of intensive care patients: perceptions of relatives, physicians and nurses. Intensive Crit Care Nurs. 2011;27(4):218-25.

14. Verhaeghe S, Defloor T, Van Zuuren F, Duijnstee M, Grypdonck M. The needs and experiences of family members of adult patients in an intensive care unit: a review of the literature. J Clin Nurs. 2005;14(4):501-9.

15. Malliarou M, Sarafis P, Karathanasi K, Sotiriadou K, Moustaka H, Zyga S. Reliability of the FS ICU-24 questionnaire for the assessment of the family satisfaction with care in the intensive care unit among health professionals. 2019;3:127-34.

16. Friedli L, WHO. Mental health, resilience and inequalities. In WHO Regional Office for Europe. 2009. https://apps.who.int/iris/handle/10665/107925. Accesed 08 Feb 2019.

17. Windle G, Bennett KM, Noyes J. A methodological review of resilience measurement scales. Health Qual Life Outcomes. 2011;9:8.

18. Min JA, Yu JJ, Lee CU, Chae JH. Cognitive emotion regulation strategies contributing to resilience in patients with depression and/or anxiety disorders. Compr Psychiatry. 2013;54(8):1190-7.

19. Davidson JR, Payne VM, Connor KM, Foa EB, Rothbaum BO, Hertzberg MA, et al. Trauma, resilience and saliostasis: effects of treatment in post-traumatic stress disorder. Int Clin Psychopharmacol. 2005;20(1):43-8.

20. Luthar SS, Cicchetti D, Becker B. The construct of resilience: a critical evaluation and guidelines for future work. Child Dev. 2000;71(3):543-62.

21. Mealer M, Conrad D, Evans J, Jooste K, Solyntjes J, Rothbaum B, et al. Feasibility and acceptability of a resilience training program for intensive care unit nurses. Am J Crit Care. 2014;23(6):e97-105.

22. Foureur M, Besley K, Burton G, Yu N, Crisp J. Enhancing the resilience of nurses and midwives: pilot of a mindfulness-based program for increased health, sense of coherence and decreased depression, anxiety and stress. Contemp Nurse. 2013;45(1):114-25.

23. Schleder LP, Parejo LS, Puggina AC, Silva MJPd. Espiritualidade dos familiares de pacientes internados em unidade de terapia intensiva \%J Acta Paulista de Enfermagem. 2013;26:71-8.

24. Reinert KG, Koenig HG. Re-examining definitions of spirituality in nursing research. J Adv Nurs. 2013;69(12):2622-34.

25. Underwood LG. The Daily Spiritual Experience Scale: Overview and Results. Religions. 2011;2(1):2950.

26. Casarini KA, Gorayeb R, Basile Filho A. Coping by relatives of critical care patients. Heart Lung. 2009;38(3):217-27. 
27. Wall RJ, Engelberg RA, Downey L, Heyland DK, Curtis JR. Refinement, scoring, and validation of the Family Satisfaction in the Intensive Care Unit (FS-ICU) survey. Crit Care Med. 2007;35(1):271-9.

28. Andreou E, Alexopoulos EC, Lionis C, Varvogli L, Gnardellis C, Chrousos GP, et al. Perceived Stress Scale: reliability and validity study in Greece. Int J Environ Res Public Health. 2011;8(8):3287-98.

29. Tsigkaropoulou E, Douzenis A, Tsitas N, Ferentinos P, Liappas I, Michopoulos I. Greek Version of the Connor-Davidson Resilience Scale: Psychometric Properties in a Sample of 546 Subjects. In Vivo. 2018;32(6):1629-34.

30. Connor KM, Davidson JR. Development of a new resilience scale: the Connor-Davidson Resilience Scale (CD-RISC). Depress Anxiety. 2003;18(2):76-82.

31. Knaus WA, Draper EA, Wagner DP, Zimmerman JE. APACHE II: a severity of disease classification system. Crit Care Med. 1985;13(10):818-29.

32. Carlson EB, Spain DA, Muhtadie L, McDade-Montez L, Macia KS. Care and caring in the intensive care unit: Family members' distress and perceptions about staff skills, communication, and emotional support. J Crit Care. 2015;30(3):557-61.

33. Jacob M, Horton C, Rance-Ashley S, Field T, Patterson R, Johnson C, et al. Needs of Patients' Family Members in an Intensive Care Unit With Continuous Visitation. Am J Crit Care. 2016;25(2):118-25.

34. Kourti M, Filntisis G, Christofilou E, Floros I, Kalergis G. Family satisfaction with the care of patients in the intensive care unit. Archives of Hellenic Medicine. 2014;31(1):60-70. Greek.

35. Chalkidi E, Bellali Th, Kyromiti A, Kosmas A, Papoti S, Kapravelos N. Exploring the psychosocial needs and satisfaction of the family of patients hospitalized in the Intensive Care Unit. Hellenic journal of nursing science 2016;9(3):44-55. Greek.

36. Sottile PD, Lynch Y, Mealer M, Moss M. Association Between Resilience and Family Member Psychologic Symptoms in Critical Illness. Crit Care Med. 2016;44(8):e721-7.

37. Rahmati M, Khaledi B, Salari N, Bazrafshan M-R, Haydarian A. The Effects of Religious and Spiritual Interventions on the Resilience of Family Members of Patients in the ICU. Shiraz E-Medical Journal. 2017;18(11).

38. Plakas S, Boudioni M, Fouka G, Taket A. The role of religiosity as a coping resource for relatives of critically ill patients in Greece. Contemp Nurse. 2011;39(1):95-105.

39. Baldacchino D, Draper P. Spiritual coping strategies: a review of the nursing research literature. J Adv Nurs. 2001;34(6):833-41.

40. Chan KS, Twinn S. An analysis of the stressors and coping strategies of Chinese adults with a partner admitted to an intensive care unit in Hong Kong: an exploratory study. J Clin Nurs. 2007;16(1):185-93.

41. Bailey JJ, Sabbagh M, Loiselle CG, Boileau J, McVey L. Supporting families in the ICU: a descriptive correlational study of informational support, anxiety, and satisfaction with care. Intensive Crit Care Nurs. 2010;26(2):114-22. 
42. Chui WY, Chan SW. Stress and coping of Hong Kong Chinese family members during a critical illness. J Clin Nurs. 2007;16(2):372-81.

43. Pochard F, Darmon M, Fassier T, Bollaert PE, Cheval C, Coloigner M, et al. Symptoms of anxiety and depression in family members of intensive care unit patients before discharge or death. $A$ prospective multicenter study. J Crit Care. 2005;20(1):90-6.

44. Paparrigopoulos T, Melissaki A, Efthymiou A, Tsekou H, Vadala C, Kribeni G, et al. Short-term psychological impact on family members of intensive care unit patients. J Psychosom Res. 2006;61(5):719-22.

45. Plaszewska-Zywko L, Gazda D. Emotional reactions and needs of family members of ICU patients. Anaesthesiol Intensive Ther. 2012;44(3):145-9.

\section{Figures}

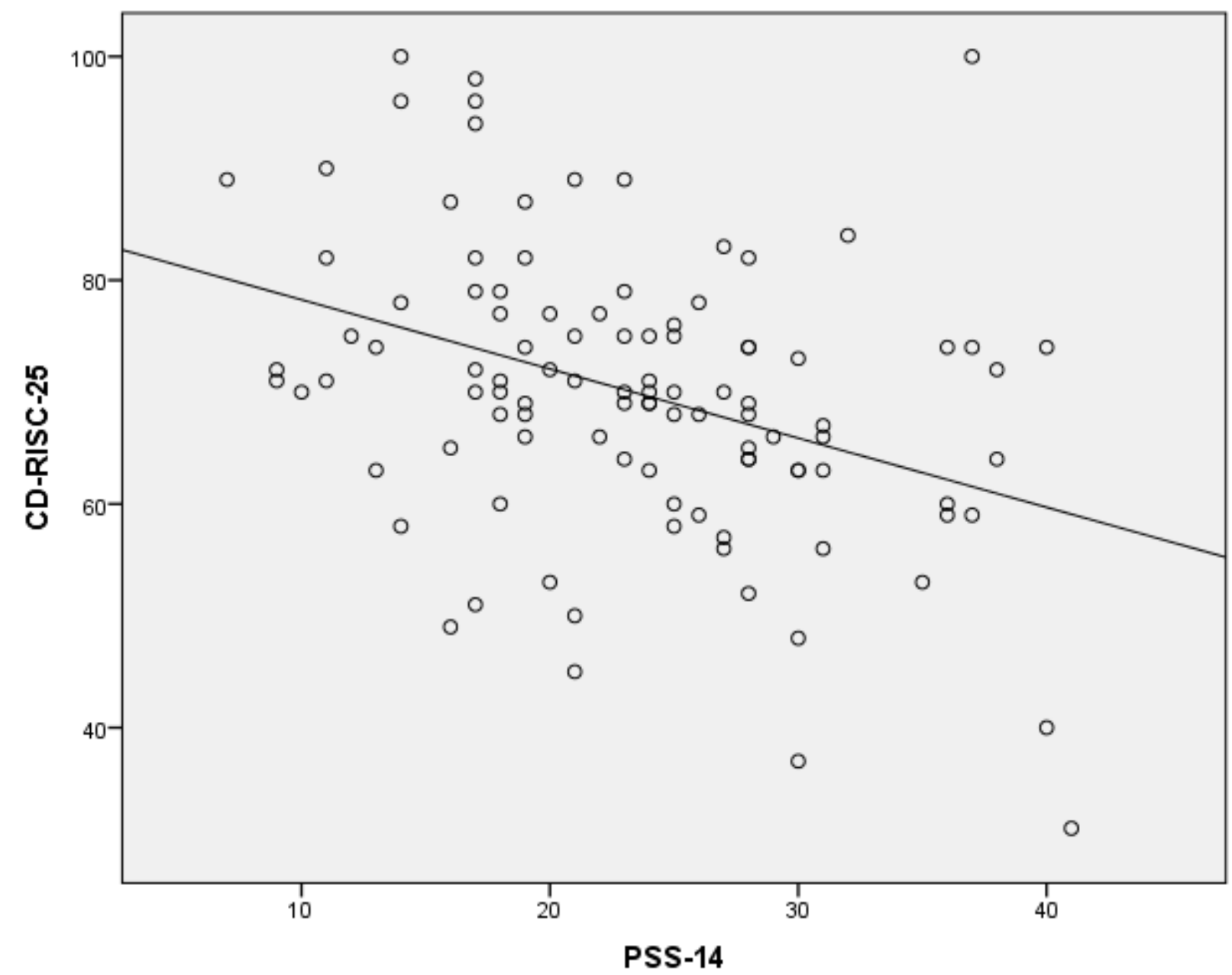

Figure 1

Correlation between PSS-14 and CD-RISC-25 


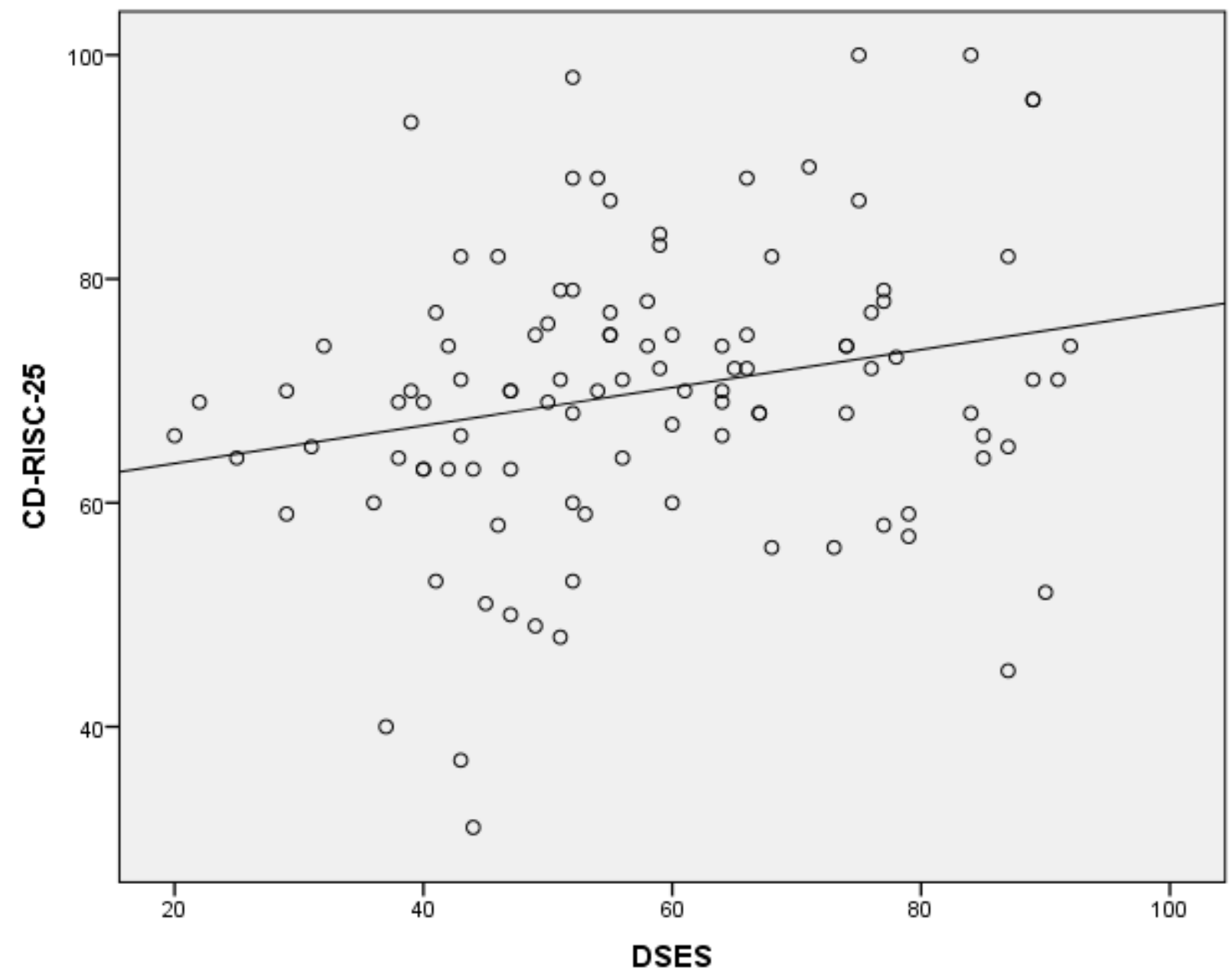

Figure 2

Correlation between DSES score and CD-RISC-25 


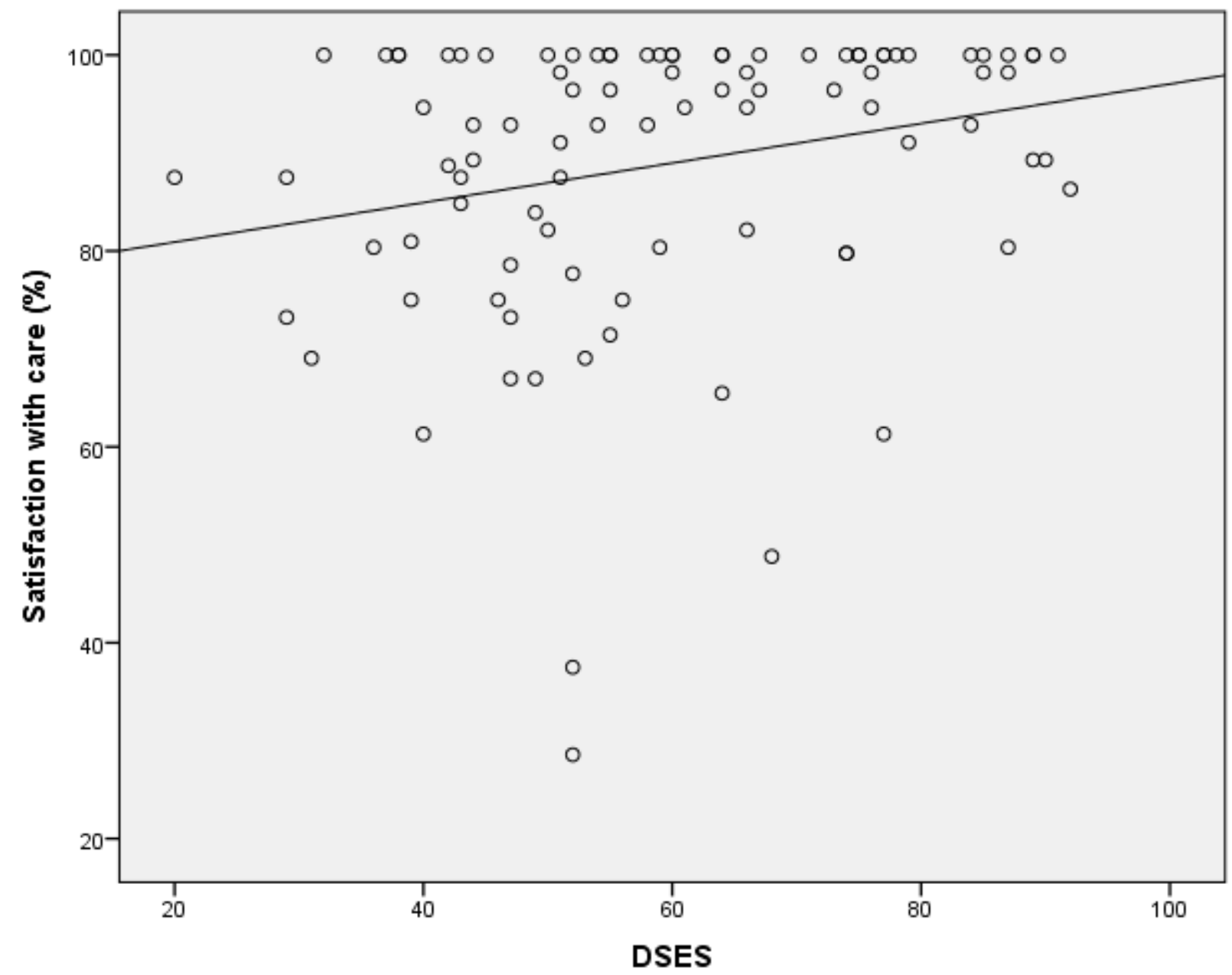

Figure 3

Correlation between DSES and satisfaction with care 


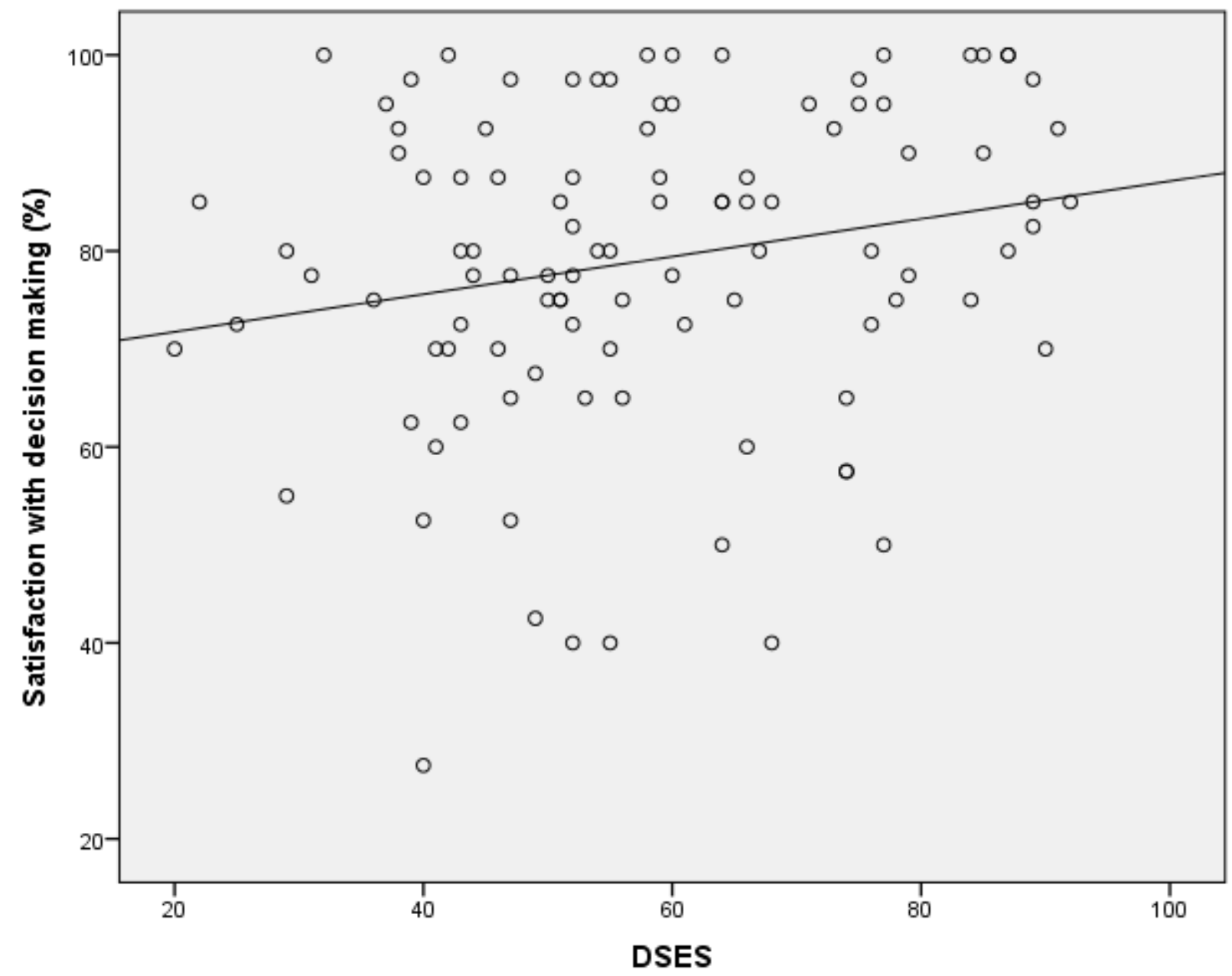

Figure 4

Correlation between DSES and satisfaction with decision making 


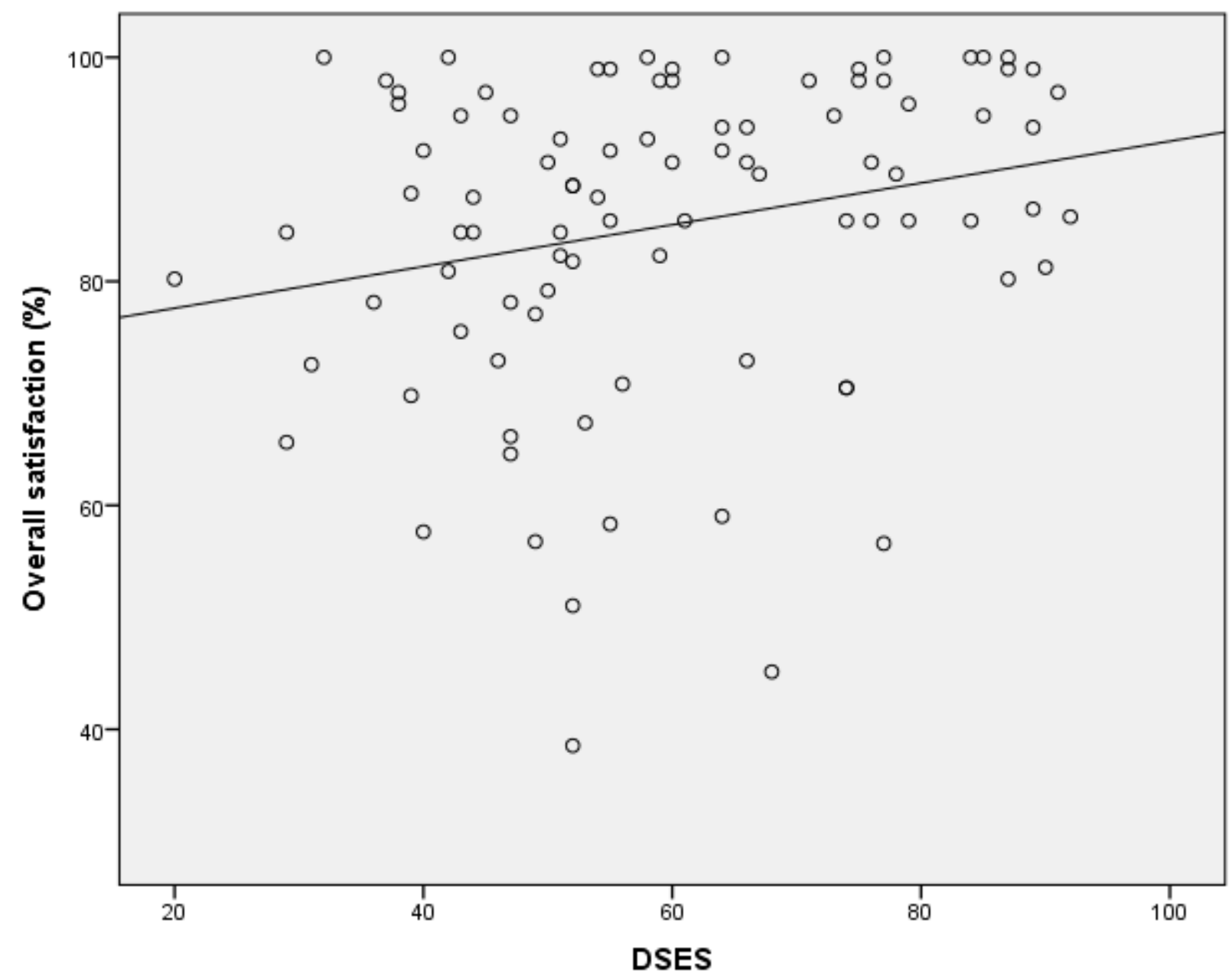

Figure 5

Correlation between DSES and overall satisfaction 


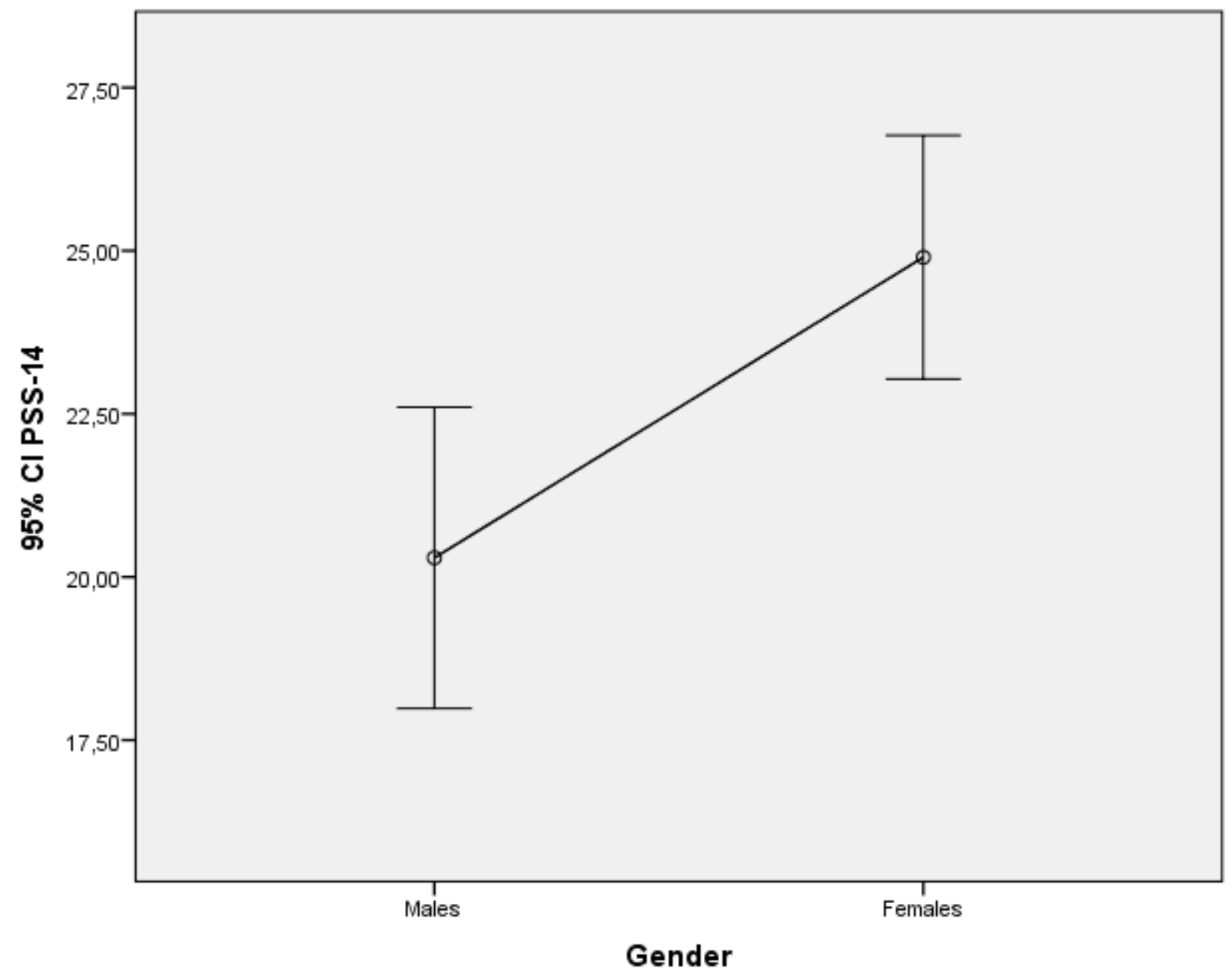

Figure 6

PSS-14 score according to participant' gender 


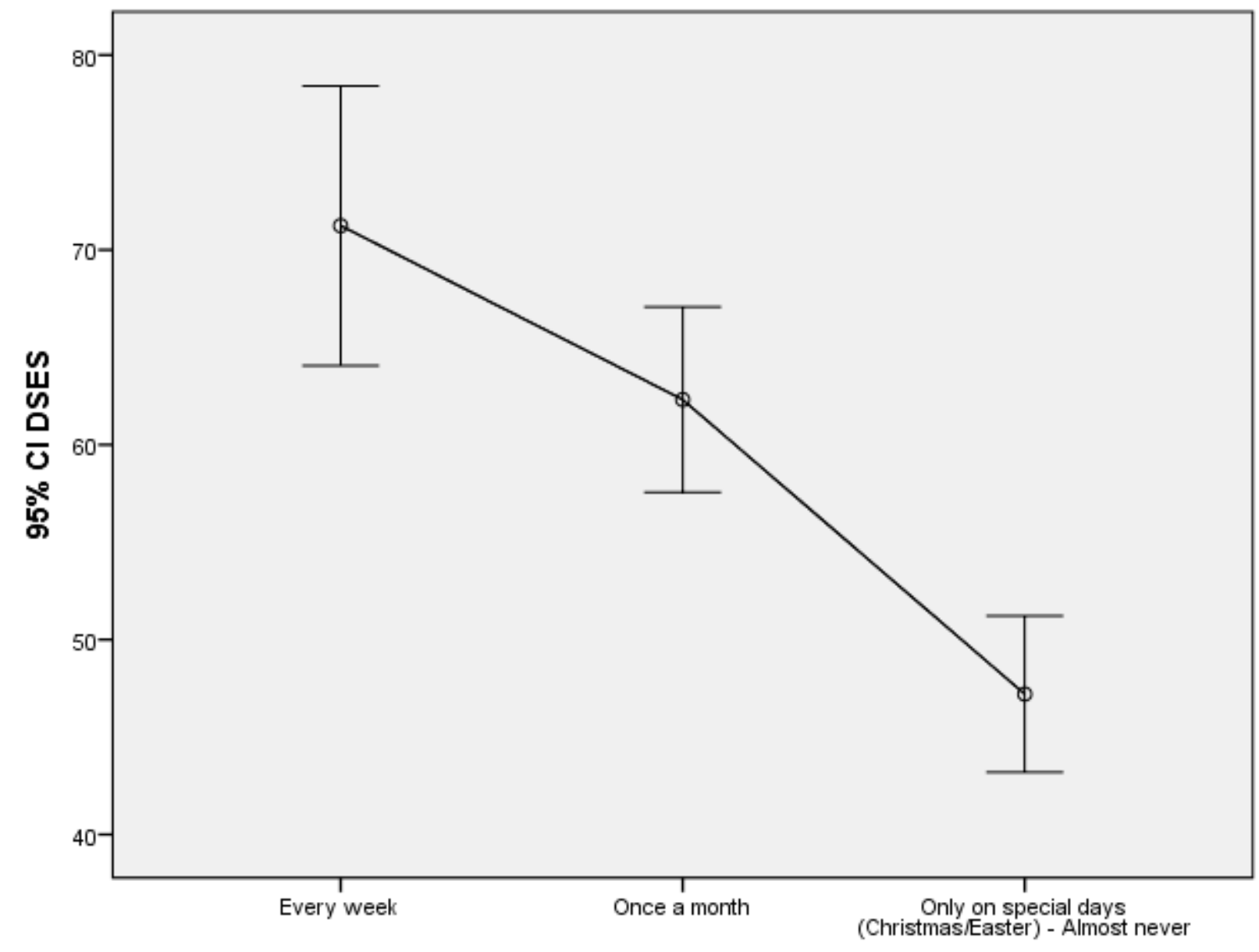

Frequency of going to the church

Figure 7

DSES score according to the frequency of going to the church 


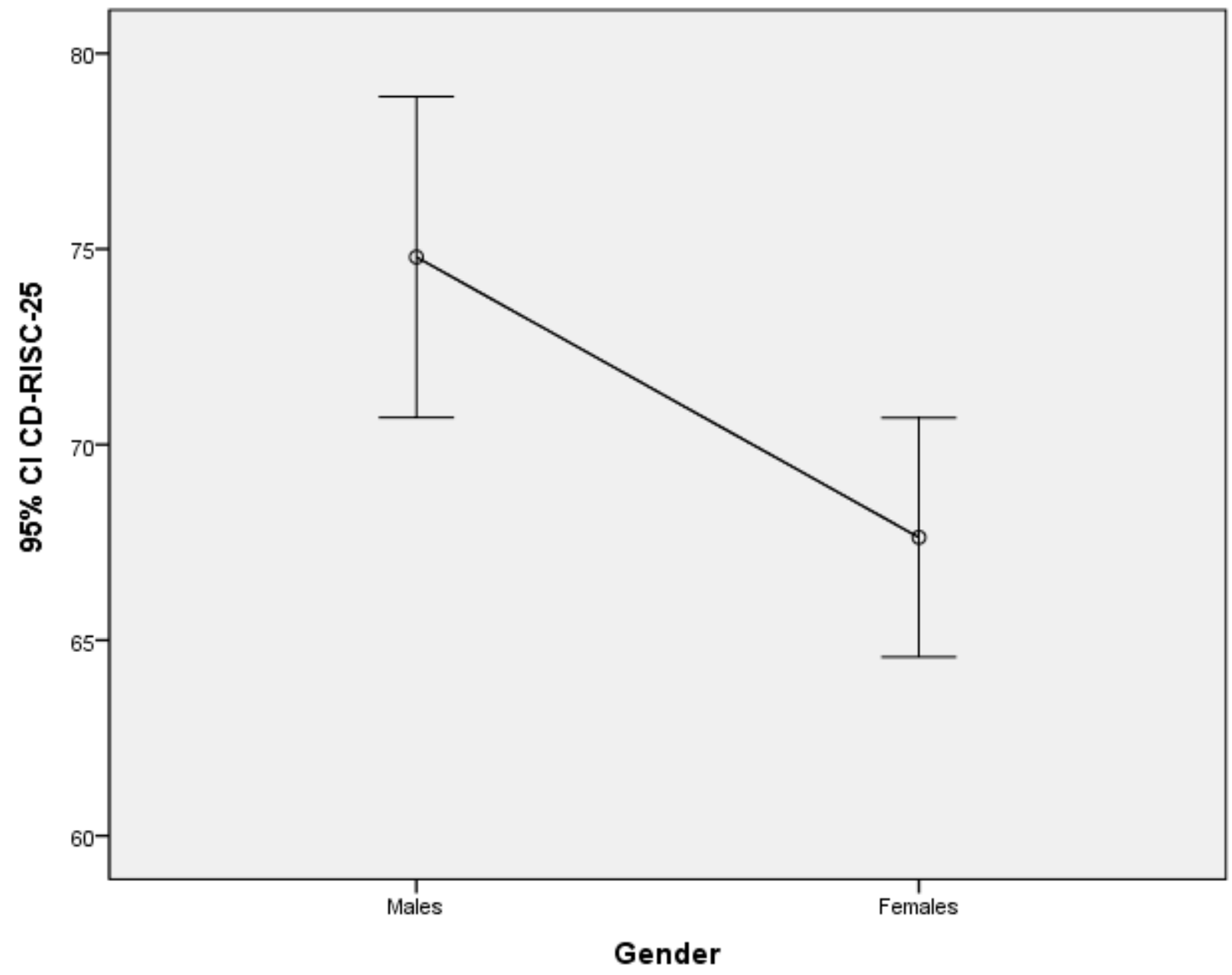

Figure 8

CD-RISC-25 score according to participants' gender 